\title{
Bactericidal/permeability-increasing protein in the reproductive system of male mice may be involved in the sperm-oocyte fusion
}

\author{
Kun $\mathrm{Li}^{1,2}$, Yue Liu ${ }^{1,2}$, Xiaoyu Xia ${ }^{1,2}$, Li Wang ${ }^{1,2}$, Meige $\mathrm{Lu}^{1,2}$, Yanqin $\mathrm{Hu}^{1,2}$ and Chen $\mathrm{Xu}^{1,2}$ \\ ${ }^{1}$ Department of Histology and Embryology, Shanghai Jiaotong University School of Medicine, 280 South Chongqing \\ Road, Shanghai 200025, China and ${ }^{2}$ Shanghai Key Laboratory of Reproductive Medicine, 280 South Chongqing Road, \\ Shanghai 200025, China
}

Correspondence should be addressed to C Xu; Email: chenx@shsmu.edu.cn

\begin{abstract}
Bactericidal/permeability-increasing protein (BPI) is a 455-residue ( $\sim 55 \mathrm{kDa})$ protein found mainly in the primary (azurophilic) granules of human neutrophils. BPI is an endogenous antibiotic protein that belongs to the family of mammalian lipopolysaccharide (LPS)-binding and lipid transport proteins. Its major function is to kill Gram-negative bacteria, thereby protecting the host from infection. In addition, BPI can inhibit angiogenesis, suppress LPS-mediated platelet activation, increase DNA synthesis, and activate ERK/Akt signaling. In this study, we found that Bpi was expressed in the testis and epididymis but not in the seminal vesicles, prostate, and solidification glands. BPI expression in the epididymis increased upon upregulation of testosterone, caused by injection of GNRH. In orchidectomized mice, BPI expression was significantly reduced, but its expression was restored to $30 \%$ of control levels in orchidectomized mice that received supplementary testosterone. The number of sperm fused per egg significantly decreased after incubation with anti-BPI antiserum. These results suggest that BPI may take part in the process of sperm-oocyte fusion and play a unique and significant role in reproduction.

Reproduction (2013) 146 135-144
\end{abstract}

\section{Introduction}

Bactericidal/permeability-increasing protein $(\mathrm{BPI})$ was first described by Weiss et al. (1978). BPI is a 455-residue $(\sim 55 \mathrm{kDa})$ protein that was originally identified in rabbit and human primary azurophilic granules of neutrophil granulocytes (Weersink et al. 1993). It can also be found on the surface of neutrophils and monocytes and in exposed epithelial areas of the nose, mouth (Canny et al. 2002, Canny \& Levy 2008), pharynx, lungs (Holweg et al. 2011), digestive tract, and organs of sensation (Geraldes et al. 2007).

BPI belongs to a family of mammalian lipopolysaccharide (LPS)-binding and lipid transport proteins. This family includes four well-characterized members, namely, BPI, LPS-binding protein (LBP), cholesteryl ester transfer protein, and phospholipid transfer protein. These proteins are $45-65 \%$ homologous at the mRNA level and are structurally and functionally related to each other (Qiu et al. 2007). For example, the genes for Bpi and $L b p$ are highly homologous and are encoded in the same region of chromosome 20. BPI and LBP are two key members of the innate immune response to Gramnegative bacteria. LBP catalyzes the extraction and transfer of individual LPS molecules to CD14, forming a monomeric LPS-CD14 complex that is a key intermediate in the delivery of LPS to MD-2/toll-like receptor 4 (TLR4) and in TLR4-dependent cell activation. In contrast, BPI, which has a higher affinity for LPS, represses inflammation by preventing LBP from delivering LPS to CD14 (Eckert et al. 2006, Palmer et al. 2011).

The BPI molecule has a highly elongated, 'boomerang' shape. The $\mathrm{N}$ - and $\mathrm{C}$-terminal domains of this protein share little sequence identity but are very similar in global architecture (Beamer 2003). The N-terminal domain is rich in cations and can specifically bind to the lipid A portion of LPS (Gazzano-Santoro et al. 1992), thereby killing Gram-negative bacteria by changing the permeability of the bacterial cell wall. LPS-neutralizing activity is also localized to the $\mathrm{N}$-terminal region of the protein. A recombinant amino-terminal fragment of BPI $(\mathrm{rBPI} 21)$ can protect animals by inhibiting the effects of Gram-negative bacteria and endotoxin (Elsbach \& Weiss 1998, Guinan et al. 2011). The function of the C-terminal domain of BPI has been less reported; all that is known is that this domain may protect BPI from degradation by intracellular enzymes and that it enhances the opsonic activity of the molecule (lovine et al. 1997).

BPI has been conserved over evolution, as orthologs have been found in a number of non-mammalian 
vertebrates and invertebrates. During the process of evolution, $\mathrm{BPI}$ in low-grade organisms may function as a surface molecule to identify environmental microbes and then kill or neutralize them (Krasity et al. 2011).

In addition to its well-documented anti-infective properties, BPI has been shown to possess additional bioactivities; for example, it has been demonstrated to act as an endogenous inhibitor of angiogenesis (der Schaft et al. 2000, 2002) via induction of endothelial cell apoptosis. In addition, BPI activates ERK and serine/ threonine protein kinase (Akt) and increases DNA synthesis in retinal pigment epithelial cells and pericytes, meanwhile reducing ischemia-induced retinal neovascularization and diabetes-induced retinal permeability (Yamagata et al. 2006). PLUNC (palate, lung and nasal epithelium clone) is a small, secreted protein that is expressed in the oropharynx and upper airways of humans, mice, and rats (Leclair 2003) and is structurally related to BPI. PLUNC inhibits Pseudomonas aeruginosa biofilm formation without acting directly as a bactericide (Bartlett et al. 2011). Auto-antibodies against BPI (BPI-ANCA) are associated with poor prognosis in cystic fibrosis, as they induce less inflammatory response than the non-ANCA-associated strains (Carlsson et al. 2011). BPI inhibits LPS-mediated platelet activation (Luo et al. 2012) and mitigates radiation-induced bone marrow aplasia and death (Guinan et al. 2011). Patients with chronic obstructive pulmonary disease present with decreased plasma levels of BPI (Chen et al. 2012).

The testis and epididymis are two important organs of the male reproductive system. The main functions of the testis are sperm production and androgen secretion. The epididymis is one of the reproductive accessory glands; its epithelium functions in absorption, secretion, and enrichment, which is consequently responsible for sperm surface remodeling, promotion of sperm maturation, sperm storage, and protection (Bedford 1967, Orgebin-Crist 1967). All these functions of the testis and epididymis are regulated by testosterone.

In this study, BPI was found in the testis and epididymis of $\mathrm{C} 57 \mathrm{BL} / 6 \mathrm{~J}$ mice but was undetectable in the seminal vesicles, prostate, and solidification glands. In the epididymis, BPI expression was regulated by testosterone levels. Immunofluorescence analysis showed BPI localization in the seminiferous tubule, caput epididymis epithelium, and sperm. Although it has been reported that BPI protein is associated with the acrosome region of mice epididymal spermatozoa (Yano et al. 2010), BPI expression was not seen in the epithelia of the corpus and cauda epididymis. Results from sperm-oocyte fusion assays indicated that anti-BPI antiserum may influence the fusion of sperm and oocytes, although the mechanism by which this occurs is still unclear and needs further investigation. Together, our data indicate that in addition to its other biological functions, BPI may play an important role in male reproduction.

\section{Materials and methods}

\section{Animals}

The Institutional Animal Care and Use Committee (IACUC) of School of Medicine, Shanghai Jiao Tong University, approved this study (SYXK (Hu) 2008 0050). All studies were performed in accordance with the Guide for the Care and Use of Laboratory Animals of the National Institutes of Health. C57BL/6) mice (male: aged 8 weeks, body weight 22-24 g; female: aged 7-9 weeks, body weight 18-20 g) were purchased from Shanghai Laboratory Animal Commission (Shanghai, China) and were accommodated in the animal facility for at least 1 week before experiments.

\section{Chemicals}

Unless otherwise stated, all reagents were purchased from Sigma-Aldrich Corporation.

\section{Reverse transcriptase-PCR}

Total RNA from the seminal vesicles, prostate, solidification glands, testes, and epididymis of mice was prepared using TRIzol Reagent (Ambion, Carlsbad, CA, USA) according to the manufacturer's instructions. Then, the cDNA from the mouse testis and epididymis was reverse transcribed with RT Master Mix (Takara, Otsu, Japan). Bpi cDNA was amplified with the forward primer, 5'-AGCAGGGAGTGGTTGAGT-3' and reverse primer, $5^{\prime}$-GATGGTGGTGATGTGGC-3'. $\beta$-Actin was amplified with the forward primer, $5^{\prime}$-CCCATCTACGAGGGCTAT- $3^{\prime}$ and the reverse primer, 5'-TGTCACGCACGATTTCC-3'.

\section{Immunofluoresence analysis}

To determine the localization of $\mathrm{BPI}$ in the mouse testis and epididymis, frozen sections of $8 \mu \mathrm{m}$ thickness were prepared and then fixed in 4\% paraformaldehyde for $20 \mathrm{~min}$ at $4{ }^{\circ} \mathrm{C}$. All subsequent incubations were performed in a humid chamber. The slides were blocked in $10 \%$ goat serum (Invitrogen) for $30 \mathrm{~min}$ at room temperature followed by a subsequent overnight incubation at $4{ }^{\circ} \mathrm{C}$ with rabbit anti-BPI antibodies (1:200 dilution) and rabbit normal IgG as a negative control. After washing, the samples were incubated with FITC-labeled goat anti-rabbit IgG (Invitrogen; 1:200 dilution) for $1 \mathrm{~h}$ at $37^{\circ} \mathrm{C}$ followed by incubation with $5 \mu \mathrm{g} / \mathrm{ml}$ propidium iodide (Wako, Osaka, Japan) for $5 \mathrm{~min}$ to counterstain the nucleus. Finally, the fluorescence-stained sections were viewed under a laser scanning confocal microscope (Carl Zeiss LSM-510, Jena, Germany). Immunofluorescence experiments were repeated at least three times.

\section{Gonadotrophin releasing hormone (GNRH) treatment}

Male mice were divided into two groups: ten animals received GNRH by i.p. injection ( $10 \mu \mathrm{g} /$ day for 5 days) and ten animals received injections of saline as a negative control. Serum testosterone concentrations and BPI expression in the testis and epididymis were analyzed. 


\section{Surgical castration}

Male mice were divided into three groups consisting of three mice each: castration, sham-operated (negative control), and no operation (normal control) groups. Mice in the castration group were killed 1-8 days after the operation.

\section{Testosterone supplement}

Testes were removed aseptically, and damage to the epididymis was avoided. Male mice were divided into three groups consisting of three mice each: the treatment group that underwent i.p. injection of $200 \mu \mathrm{l}$ testosterone at a concentration of $2 \times 10^{-7} \mathrm{~mol} / \mathrm{l}$, the control group that underwent i.p. injection of physiological saline, and the blank control group that had no treatment. The mice were killed the day after testosterone treatment. Serum testosterone concentrations and BPI expression in the epididymis were analyzed in three independent experiments.

\section{Serum testosterone detection}

Blood $(200 \mu \mathrm{l})$ from each mouse was collected from the inner canthus. Blood samples were allowed to clot for $30 \mathrm{~min}$ before centrifugation for $15 \mathrm{~min}$ at $1000 \mathrm{~g}$. The serum was removed, followed by quantitative analysis of testosterone levels with a testosterone ELISA Kit (R\&D, Minneapolis, MN, USA) according to the manufacturer's protocol.

\section{Quantitative real-time $P C R$}

SYBR green-based quantitative real-time PCR (qPCR) assays for the quantitative detection of $\mathrm{BPI}$ were performed to analyze $\mathrm{Bpi}$ gene expression in the testes and epididymis. The cDNA was obtained as previously described. Bpi primers were as follows: forward primer, 5'-CCCGCCAGTAATGAGGTT-3'; reverse primer, 5'-CAGGGTCATCTTCAAGGTTC-3'. Primers for the $\beta$-actin gene, which served as an internal control, were as follows: forward primer, 5'-AGGTGACAGCATTGCTTCTG-3'; reverse primer, 5'-GCTGCCTCAACACCTCAAC-3'. QPCR was performed using the Applied Biosystems 7500 real-time PCR
System, according to the manufacturer's protocol. The $2^{-\Delta \Delta \mathrm{Ct}}$ method was used to analyze the data.

\section{Preparation of protein specimens}

Mice testis and epididymis were homogenized using T-PER Tissue Protein Extraction Reagent (Pierce, Rockford, IL, USA) supplemented with a protease inhibitor cocktail (Ameresco, Solon, $\mathrm{OH}, \mathrm{USA}$ ). Protein extracts were incubated in a rotating ice bath for at least $30 \mathrm{~min}$ to allow proteins to dissolve completely, followed by centrifugation at $12000 \mathrm{~g}$ for $10 \mathrm{~min}$. The supernatant was saved, and protein concentration was determined using the Pierce BCA Protein Assay Kit.

\section{Western blot analysis}

Protein samples $(30 \mu \mathrm{g})$ were separated by SDS-PAGE and then transferred to PVDF membranes (Millipore, Billerica, MA, USA) using a semi-dry transfer apparatus (Bio-Rad). Membranes were blocked in 5\% BSA. Immunoblotting was performed with rabbit anti-BPI-C polyclonal antibodies at a suitable dilution followed by incubation with secondary antibody conjugated to HRP (Abgent, San Diego, CA, USA) at a 1:5000 dilution. Signals were detected by ECL (Millipore) according to the manufacturer's protocol. $\beta$-Actin (1:5000; Abcam, Cambridge, MA, USA) served as the internal reference.

\section{Gamete preparation}

Female $\mathrm{C} 57 \mathrm{BL} / 6 \mathrm{~J}$ mice were superovulated by abdominal injection of $10 \mathrm{IU}$ of pregnant mare's serum gonadotropin (PROSPEC, Rehovot, Israel) followed by injection of $10 \mathrm{IU}$ human chorionic gonadotropin (hCG; Li Zhu drug plant, Zhuhai, China) after 46-48 h. Cumulus-enclosed egg complexes were collected from the oviducts 15-16 h posthCG injection and treated with $0.1 \%$ hyaluronidase in Medium 16 (M16) to disperse the cumulus cells. The zona pellucida was removed with $0.6 \%$ proteinase $\mathrm{K}$, after which the eggs were incubated in M16 containing 3\% BSA at $37{ }^{\circ} \mathrm{C}, 5 \% \mathrm{CO}_{2}$ for 30-60 min.

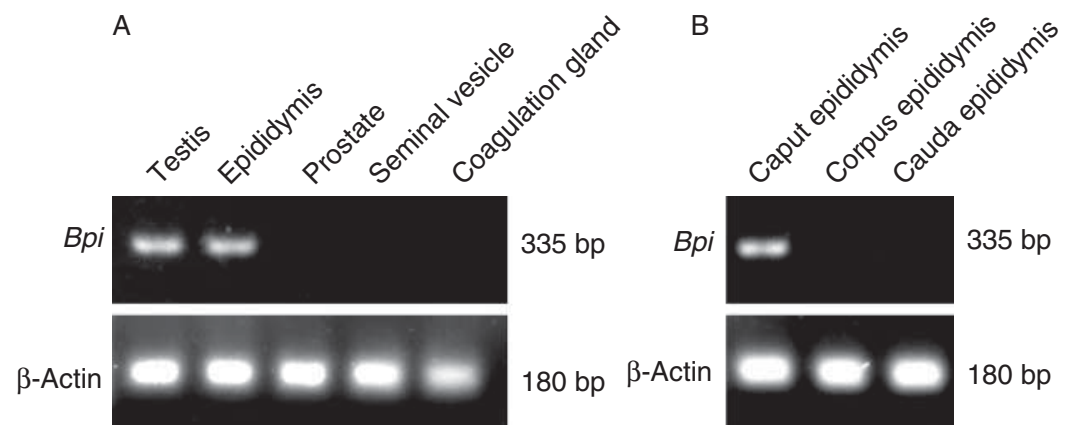

Figure 1 Analysis of Bpi mRNA expression in the male mouse reproductive tract by RT-PCR. (A) Upper section shows amplification of the Bpi gene from total RNA of adult mouse (8 weeks) testes, epididymis, prostate, seminal vesicles, and coagulation gland respectively. The lower section shows to amplification of the $\beta$-actin gene that corresponds with the genes in the upper lanes. (B) Upper section shows amplification of the Bpi gene from total RNA of adult mouse (8 weeks) caput epididymis, corpus epididymis, and cauda epididymis respectively. The lower section shows amplification of the $\beta$-actin gene that corresponds to genes in the upper lanes. 
Mature spermatozoa were collected from the epididymal cauda of $\mathrm{C} 57 \mathrm{BL} / 6 \mathrm{~J}$ male mice by rough cutting in $1.5 \mathrm{ml}$ of M16 containing 3\% BSA. Motile spermatozoa were allowed to swim out for 10-15 min, after which the tissue was removed from the medium. One part of the spermatozoa was cultured for $2 \mathrm{~h}$ in M16 (containing $3 \mathrm{mg} / \mathrm{ml} \mathrm{BSA}$ and $5 \mu \mathrm{mol} / \mathrm{l}$ calcium ionophore $\mathrm{A} 23187$ ) at $37^{\circ} \mathrm{C}, 5 \% \mathrm{CO}_{2}$. The rest of the spermatozoa were cultured for $90 \mathrm{~min}$ in $\mathrm{M} 16$ containing $3 \mathrm{mg} / \mathrm{ml} \mathrm{BSA}$ at $37^{\circ} \mathrm{C}, 5 \% \mathrm{CO}_{2}$, which allowed them to capacitate and undergo spontaneous acrosome reaction. Next, spermatozoa (adjusted to $10^{7} \mathrm{sperm} / \mathrm{ml}$ ) were incubated for $40 \mathrm{~min}$ in the presence or absence of the same dilutions of purified rabbit anti-mouse BPI-C antiserum (inactivated complement), purified rabbit anti-mouse BPI-N antiserum (inactivated complement), pre-immunized rabbit serum, or wash buffer (control), followed by a 1:40 dilution with M16 containing 3\% BSA for use in the sperm-oocyte fusion assay. The final sperm concentration was $2.5 \times 10^{5} \mathrm{sperm} / \mathrm{ml}$.

\section{Sperm-oocyte fusion assay}

For every sperm-oocyte fusion assay, all oocytes and spermatozoa used in an experiment were combined from several female and male mice and then randomly divided into each group. Zona pellucida-free oocytes were directly added to the sperm suspensions that were prepared as described earlier, and the gametes were co-incubated for $3 \mathrm{~h}$ at $37{ }^{\circ} \mathrm{C}, 5 \% \mathrm{CO}_{2}$. Then, loosely bound spermatozoa were removed from the oocytes by gentle pipetting. Next, the oocytes were fixed in $4 \%$ paraformaldehyde for $15 \mathrm{~min}$ and then treated with Hoechst 33342 for 10 min to stain the chromatin. Finally, images were collected using a laser scanning confocal microscope and results were obtained as the average number of penetrating sperm per oocyte. Each assay was repeated at least three times.

\section{Statistical analysis}

All values are presented as mean \pm S.E.M., and statistical analysis of the data was carried out using SAS 8.0. Data was assessed for normality using the Shapiro-Wilk test. Statistically significant differences in the serum testosterone in gonadotropin-releasing hormone $(\mathrm{GnRH})$ treatment, surgical castration and testosterone supplement after surgical castration, mRNA values, and the numbers of sperm fused to oocytes were analyzed using ANOVA. The Student-Newman-Keuls test was used to account for variance. Pearson correlations were performed to test the correlation between serum testosterone concentration and BPI mRNA expression in the epididymis. The false discovery rate was utilized to adjust the level of significance to account for multiple comparisons. Statistical significant difference was considered to be $P<0.05$.

\section{Results}

\section{Bpi mRNA expression in the reproductive system of male mice}

In order to analyze Bpi mRNA expression in the reproductive system of adult male mice, qPCR was
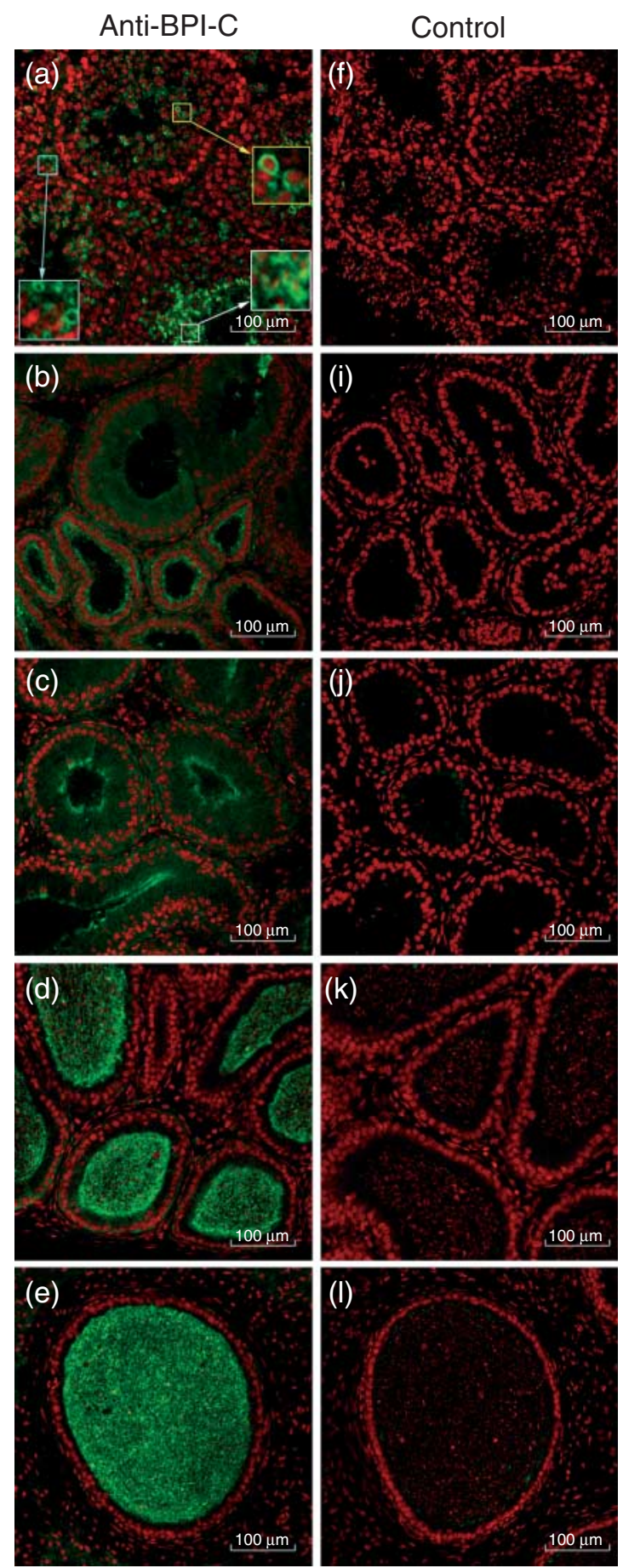

Figure 2 Localization of BPI protein in the adult mouse testis and epididymis. BPI-positive signals had a green fluorescence, and the nucleus, which was counterstained with propidium iodide, had a red fluorescence. (a, b, c, d and e) These images represent the adult mouse (8 weeks) testis, efferent duct, caput epididymis, corpus epididymis, and cauda epididymis respectively. Enlargement of the seminiferous tubule in (A) is indicated with a yellow box, enlargement of the interstitial tissue is indicated with a light blue box, and enlargement of the sperm from the testis is indicated with a white box. (f, g, h, i and j) The negative controls (rabbit normal $\lg G$ ) corresponding to images (a, b, c, d and e) respectively. 
performed. Bpi mRNA was remarkably expressed in the testis and epididymis but not in the other organs examined, including the seminal vesicles, prostate, and solidification glands (Fig. 1A). With regard to the epididymis, which is divided into three main regions: the caput, corpus, and cauda, Bpi expression was only detected in the caput epididymis epithelium but not in the epithelia of the corpus and cauda epididymis (Fig. 1B).

\section{BPI localization in the testis and epididymis}

Immunofluoresence analysis with an anti-BPI-C terminal polyclonal antibody (Supplementary Figure 1, see section on supplementary data given at the end of this article) was performed to determine the localization of $\mathrm{BPI}$ in the mouse testis and epididymis. A positive BPI signal was seen in spermatocytes and spermatids (Fig. 2a, Supplementary Figure 2), as well in mature spermatozoa (Fig. 2e), indicating that BPI was expressed throughout the processes of spermatogenesis in the testis and sperm maturation in the epididymis. BPI was also expressed in Leydig cells. Consistent with the gPCR data, BPI expression in the epididymis was confined to the epithelia of the efferent duct and caput epididymis. BPI expression in the efferent duct was higher than that in the caput epididymis (Fig. 2b, c, d and e).

\section{Testosterone-influenced Bpi expression}

To determine the effect of increased testosterone levels on Bpi expression, GNRH was used to enhance testosterone synthesis and secretion in male mice. After 5 days of i.p. injection with GNRH, serum testosterone levels increased more than 30-fold compared with that in control mice that were only treated with saline (Fig. 3A, $P<0.01$ ). In addition to increased testosterone levels, there was an approximate doubling of Bpi mRNA expression in the epididymis (Fig. 3B, $P<0.05$ ). Nevertheless, Bpi expression in the testis did not increase upon GNRH treatment (Fig. 3C). These results indicated that Bpi expression in the epididymis was more sensitive to the testosterone level.

In order to assess the effect of decreased testosterone on BPI expression, surgical castration was carried out to decrease testosterone synthesis. After castration, serum testosterone concentrations began to decrease on the first day and were maintained at stable low levels over the following days (Fig. 4A, $P<0.01$ ). Interestingly, similar to changes in serum testosterone levels after castration, Bpi mRNA expression levels in the epididymis also decreased to about $20 \%$ of those in the control group, the day after surgical castration. After 3 days, Bpi expression decreased to levels of $10 \%$ or less than that in the control mice (Fig. 4B, $P<0.01$, Supplementary Figure 3). Accordingly, serum testosterone
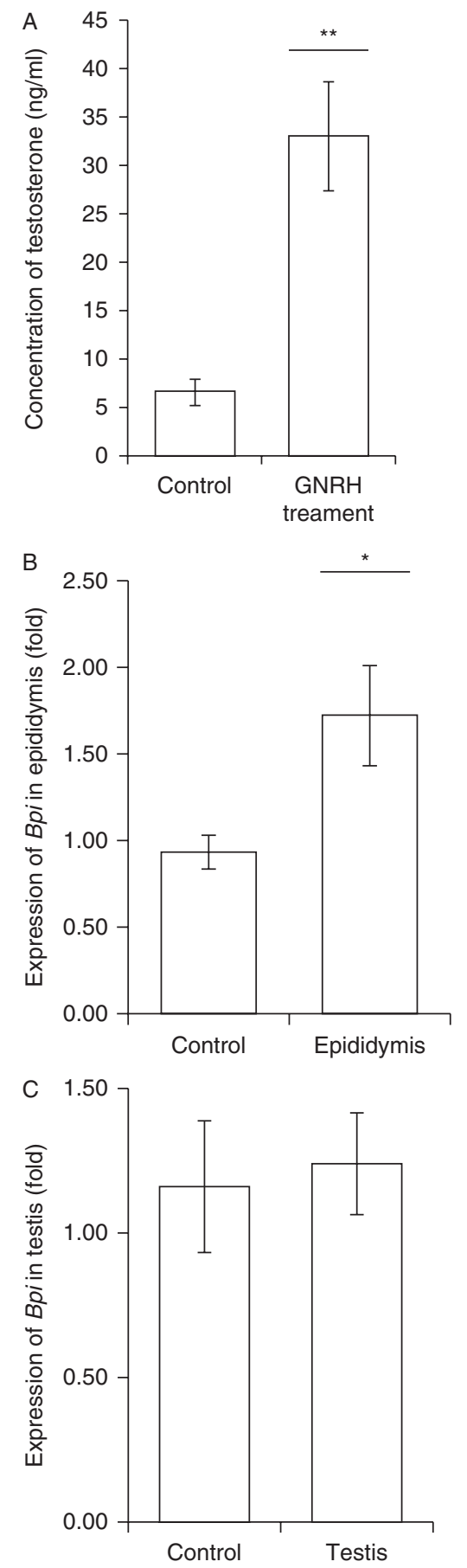

Figure 3 Serum testosterone concentrations and Bpi mRNA levels after stimulation with GNRH. (A) After the mouse was stimulated with GNRH for 5 days, ELISA was performed to determine the serum testosterone concentration. The control group was treated with physiological saline instead of GNRH. Data are presented as mean \pm s.D. and showed statistical significance $(* * P<0.01)$ when comparing the GNRH and control groups. (B and C) After the mouse was stimulated with GNRH for 5 days, qPCR was carried out to analyze Bpi mRNA expression in the epididymis and testis. The control group received physiological saline instead of GNRH. Data are presented as mean \pm s.D. and showed statistical significance $\left({ }^{*} P<0.05\right)$ when comparing the GNRH and control groups. 

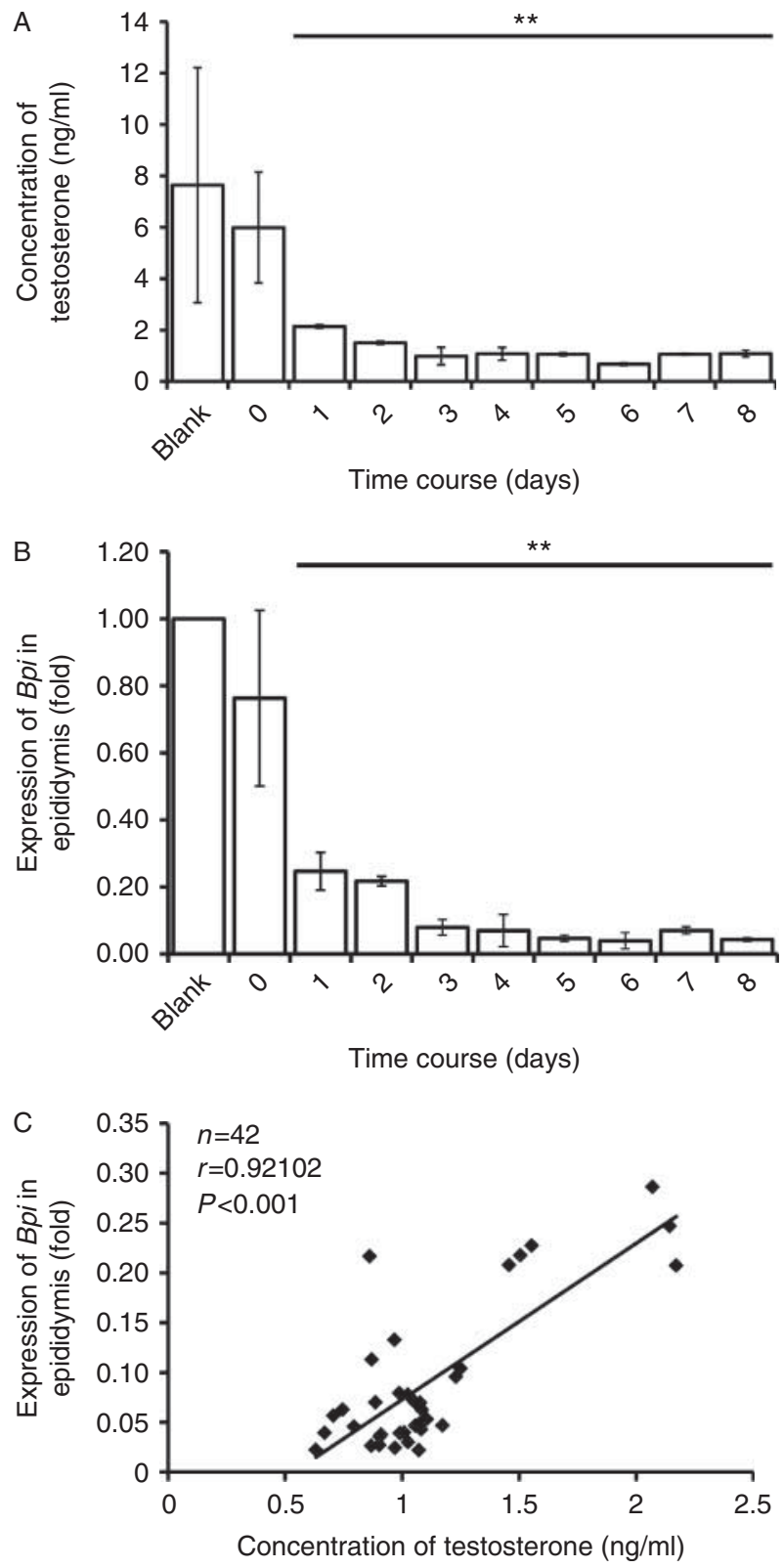

Figure 4 Serum testosterone concentrations and Bpi mRNA levels after surgical castration. (A) At 1 to 8 days after surgical castration, an ELISA was performed to determine serum testosterone concentrations. Sham operation was used as day 0 , and the group that did not undergo an operation was the blank. The ELISA was performed three times. Data are presented as mean \pm s.D., and showed statistical significance $\left({ }^{* *} P<0.01\right)$ when comparing the castration group to the control and blank groups. (B) At 1 to 8 days after surgical castration, qPCR analysis was performed to analyze Bpi mRNA expression in the epididymis. Sham operation was used as day 0 , and the group that did not undergo an operation was the blank. Experiments were performed three times. Data are presented as mean \pm s.D. and showed statistical significance $\left({ }^{* *} P<0.01\right)$ when comparing the castration group to the control and blank groups. (C) Correlation between serum testosterone concentration and Bpi mRNA expression in the epididymis. concentrations in male mice positively correlated with Bpi mRNA expression levels in the epididymis (Fig. 4C, $r=0.91, P<0.001)$. The mice were given testosterone in order to slow down the decrease of testosterone. Daily i.p. injection of testosterone at a concentration of $2 \times 10^{-7} \mathrm{~mol} / \mathrm{l}$ led to retention of serum testosterone concentrations at over half of physiological concentrations compared with only $25 \%$ in the control group (Fig. 5A, $P<0.05$ ). Although Bpi expression decreased to about $30 \%$ of that in the blank group (Fig. $5 B, P<0.01$ ), the expression of Bpi was almost $150 \%$ compared with the control group (Fig. 5B, $P<0.05$ ). These results indicate that $\mathrm{Bpi}$ expression in the epididymis is influenced by testosterone levels.

BPI protein expression in response to the different treatments was determined by western blot analysis. As shown in Fig. 6, protein expression upon GNRH treatment and surgical castration was in accordance with Bpi mRNA levels. In other words, Bpi expression in the testis seemed unrelated to testosterone levels; however, there was a correlation in the epididymis.

\section{BPI plays a role in the sperm-oocyte fusion process}

As shown in Figs 7, 8 and Supplementary Figure 4 the number of sperm fused to oocytes significantly decreased after incubation with either anti-BPI-N or anti-BPI-C antiserum compared with those incubated with pre-immunized rabbit serum as a control $(P<0.01)$. The results indicated that both the $\mathrm{N}$ - and $\mathrm{C}$-terminal domains of the BPI protein might play a significant role in the sperm-oocyte fusion process.

\section{Discussion}

The male reproductive system is an open duct from the body to the external environment. Bpi is expressed in the male reproductive system (Lennartsson et al. 2005) and has been reported to have anti-Gram-negative bacteria activity. Although our results confirmed that Bpi is expressed in the male reproductive tract, it was unexpected to find that Bpi gene expression was localized in the testis and epididymis, and not in the seminal vesicles, prostate, and solidification glands, which are the organs closer to the external environment. This suggests that in the male reproductive system, BPI may not function as just an anti-microbial protein, as previously described in other organs.

In the testis, a BPI-positive signal was found in Leydig cells, spermatocytes, spermatids, and sperm in the seminiferous tubule. BPI protein expression in the epididymal epithelial cells showed significant regional differences, which indicates that it may have different functions. The expression of BPI in the epithelia of the efferent duct and caput epididymis suggests that it may play a critical role in the early stage of epdidymal 

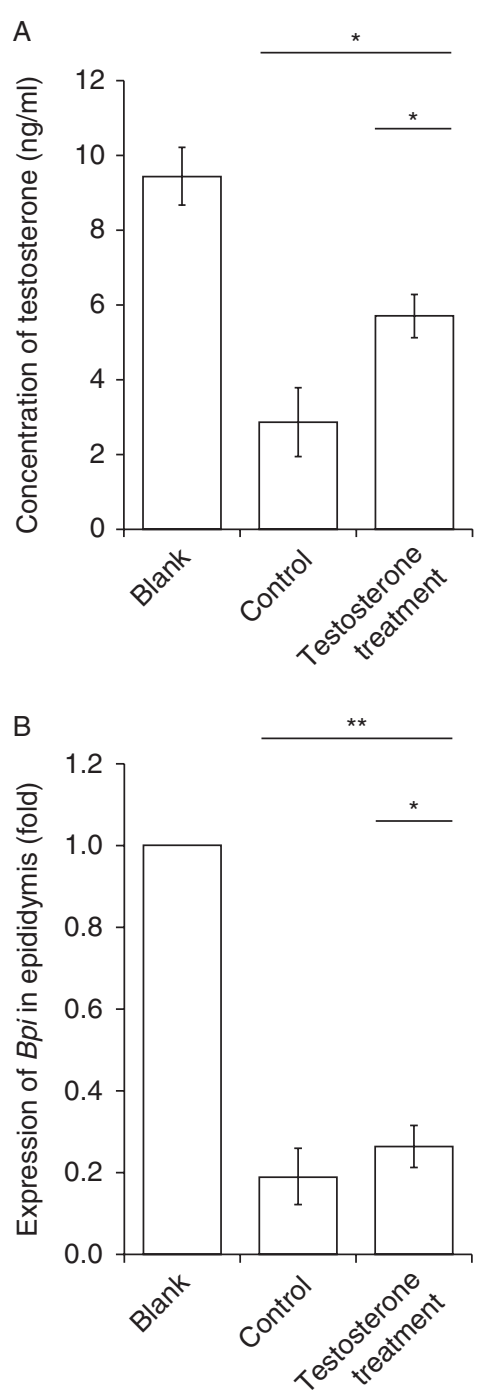

Figure 5 Serum testosterone concentrations and the Bpi mRNA levels after castrated mice were stimulated with testosterone. (A) After castration, mice were stimulated with $10^{-7} \mathrm{~mol} / \mathrm{l}$ testosterone for 1 day followed by ELISA to determine the serum testosterone concentration. The control group received saline instead of testosterone, while the blank group did not undergo an operation. Data are presented as mean \pm s.D. and showed statistical significance $\left({ }^{*}\right.$ with shorter bar, $P<0.05$ ) when comparing the testosterone treatment group with the control group. Data also showed statistical significance $\left({ }^{*}\right.$ with longer bar, $P<0.05)$ when comparing the testosterone treatment group and the control group with the blank group. (B) qPCR analysis was used to analyze Bpi mRNA expression in the epididymis in aforementioned three groups. Data are presented as mean \pm S.D. and showed statistical significance $\left({ }^{*}\right.$ with shorter bar, $P<0.05$ ) when comparing the testosterone treatment and control groups. Data also showed statistical significance (** with longer bar, $P<0.01$ ) when comparing the testosterone treatment and control groups with the blank group.

maturation. As our results show, in the seminiferous tubules, BPI was expressed in spermatocyte cells, spermatid cells, and spermatozoa that passed though the epididymis. BPI secreted by the efferent duct and caput epididymis may be continuously absorbed onto spermatozoa. In other words, BPI is expressed throughout the processes of spermatogenesis in the testis, and sperm maturation in the epididymis. It is noteworthy that BPI-positive signals were strong in Leydig cells. BPI belongs to a family of mammalian LPS-binding and lipid transport proteins. Two members of this family have been identified that are related to lipid transport. One of the important functions of Leydig cells is producing androgens that are synthesized using lipid as raw material. We need to do more research to confirm whether BPI has a function of lipid transport in Leydig cells. In addition, it has been reported that BPI is localized in the matrix of the acrosome and attaches to the spermatozoa plasma membrane surface in the acrosomal region (Yano et al. 2010), suggesting that BPI may play a role in fertilization in addition to its anti-microbial function.

Testosterone is a steroid hormone that is primarily produced by testicular Leydig cells (Haider 2004). In addition to its traditional role in spermatogenesis, and development and maintenance of primary and secondary sex characteristics, testosterone has several other biological functions. Preliminary experiments have indicated that BPI expression peaks at sexual maturity and is lower in older or younger men, which made us speculate that there may be some relationship between $\mathrm{BPI}$ expression and androgen. Here, we found that Bpi expression in the epididymis was altered according to either increases or decreases in serum testosterone concentrations. In particular, after castration, the expression of $\mathrm{Bpi}$ in the epididymis was extremely low, and the expression of Bpi was restored to $30 \%$ of control

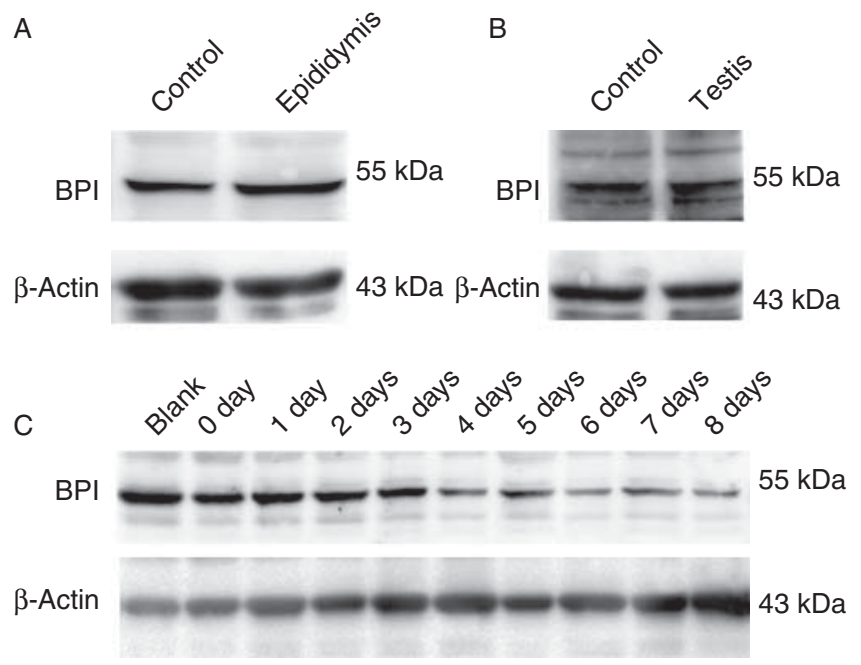

Figure $6 \mathrm{BPI}$ expressed as determined by western blot analysis. The signal at $50 \mathrm{kDa}$ represents the BPI protein. The signal at $43 \mathrm{kDa}$ represents $\beta$-actin. (A) Protein expression of $\mathrm{BPI}$ and $\beta$-actin in the epididymis after stimulation with GNRH. (B) Protein expression of BPI and $\beta$-actin in the testis after stimulation with GNRH. (C) Protein expression of $\mathrm{BPI}$ and $\beta$-actin in the epididymis after surgical castration at each time point. 

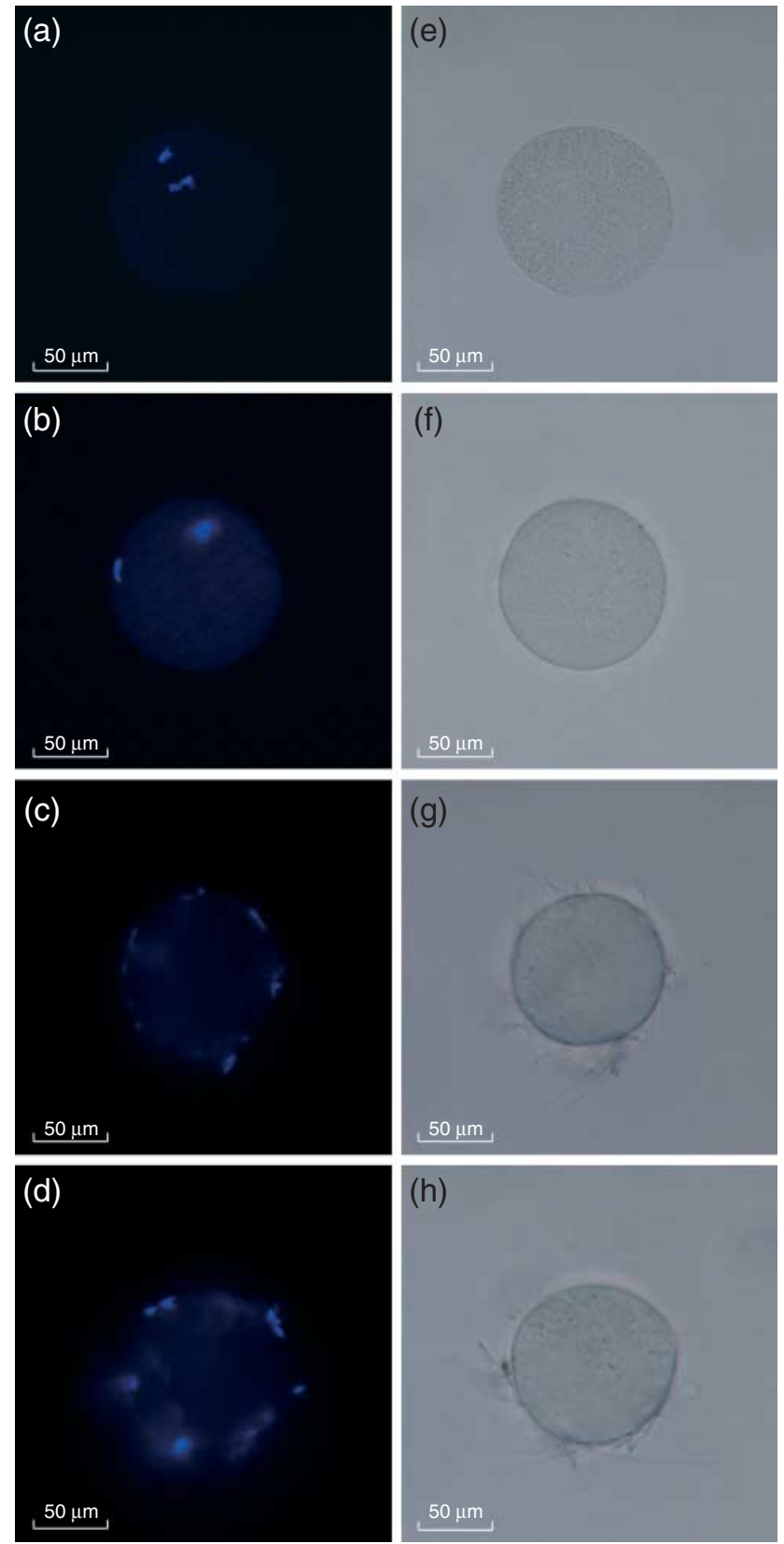

Figure 7 Images of sperm-oocyte fusion. The head of the sperm had blue fluorescence. And the blue fluorescence picture of each operation was placed in the left array. (a, b, c and d) These images represent incubation with anti-BPI-C antiserum, anti-BPI-N antiserum, negative control, and blank control respectively. (e, $f, g$ and $h$ ) These images represent the white photos from the images shown in (a, b, c and d).

levels by administration of testosterone. These results corroborate our speculation.

It is reported that the synthesis and secretion of epididymal proteins are regulated by temperature (Belleannee et al. 2012), as well as by endocrine (Primiani et al. 2007, Sipila et al. 2011), paracrine (Turner et al. 2007a, 2007b, Belleannee et al. 2012) and lumicrine factors (Turner \& Bomgardner 2002, Sipila et al. 2011,
Turner 2011), which are from the testis or from upstream regions of efferent ducts. Epididymal BPI may be regulated by these factors in addition to testosterone, which may explain the fact that Bpi expression was restored to $30 \%$ of its normal levels in orchidectomized mice treated with testosterone. However, $\mathrm{BPI}$ expression in the testis was less sensitive to increases in testosterone compared with BPI expression in the epididymis upon GNRH treatment. This may be due to the insensitivity of germ cells to androgens. Together, these results suggest that a certain amount of testosterone is essential for $\mathrm{BPI}$ expression, and high levels of testosterone may increase BPI expression in the epididymis. In fact, it has been reported that a number of proteins in the testis and epididymis involved in sperm maturation and fertilization, such as glutathione peroxidase (Klapcinska et al. 2008) and $\gamma$-glutamyl transferase (Haring et al. 2012), are regulated by testosterone and play a role in reproductive activities. Therefore, the regulation of BPI expression by testosterone suggests that BPI may play a crucial role in fertilization.

The mechanism underlying the process of spermoocyte fusion remains unclear. It is generally thought that the mammalian acrosome reaction is induced by the zona pellucida. There are a number of proteins, such as acrosin, sperm adhesion molecule 1 (Hardy et al. 2004, sperm-oocyte binding antigen 2 (Lefevre et al. 1997), SKP2 (FLB1; Boue et al. 1995), fertilization antigen (Naz 2002), and cystatin-related epididymal spermatogenic protein (Wang et al. 2012)), that take part in the acrosome reaction and sperm-oocyte fusion process. For instance, it has been demonstrated that cystatinrelated epididymal spermatogenic protein has both anti-microbial functions and a role in the sperm-oocyte fusion process. BPI is located in the matrix of the acrosome and attaches to the spermatozoa plasma

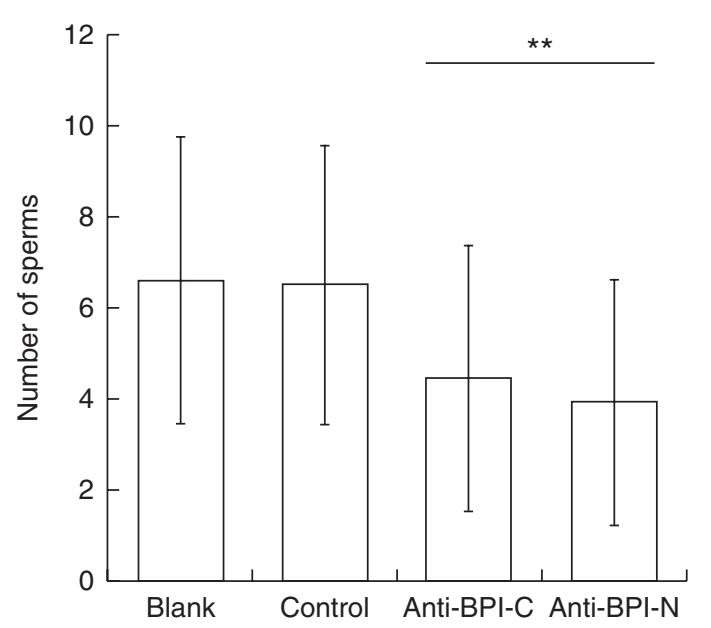

Figure 8 Statistical analysis of sperm-oocyte fusion between each operation. Data are presented as mean \pm s.D. Data showed statistical significance $(* * P<0.01)$ when comparing anti-BPI-C antiserum and anti-BPI-N antiserum operation groups with control and blank groups. 
membrane surface of the acrosomal region (Yano et al. 2010). Data from our sperm-oocyte fusion assay suggest that both the $\mathrm{N}$ - and C-terminal domains of BPI may be directly involved in the sperm-oocyte fusion process. When sperm fuse with an oocyte, the microenvironment around the gamete is not sterile. BPI may play an indirect role in sperm-oocyte fusion by the interaction between the protein and microorganism. There are plenty of microorganisms in our body, especially in the intestinal tract, that are in mutualism with us. They are parts of us. Interestingly, it was recently reported that BPI may have a role in the mutualism between the Hawaiian bobtail squid (Euprymna scolopes) and the bioluminescent bacterium (Vibrio fischeri) (Krasity et al. 2011). Thus, we speculate that BPI may also be involved in spermoocyte fusion by its function in mutualism. For example, BPI on sperm may not directly interact with the oocyte but may serve as an intermediary between the oocyte and microorganisms, thereby playing the role of a bridge molecule. In other words, BPI may interact with some bacterium, and the anti-microbial role of BPI may be involved in the normal process of sperm-oocyte fusion.

\section{Conclusions}

Bpi expression was only found in the testis and caput epididymis and not in other reproductive accessory glands. Testosterone levels regulated BPI expression, In addition, anti-BPI antiserum incubated with sperm suppressed sperm-oocyte fusion. These results suggest that BPI may not only function as an anti-microbial protein but may also play a role in mammalian fertilization.

\section{Supplementary data}

This is linked to the online version of the paper at http://dx.doi. org/10.1530/REP-13-0127.

\section{Declaration of interest}

The authors declare that there is no conflict of interest that could be perceived as prejudicing the impartiality of the research reported.

\section{Funding}

This work was supported by the Science and Technology Commission of Shanghai Municipality (no. 10DZ2270600), Shanghai Leading Academic Discipline Project (no. S30201), and the Key Project of Shanghai Science and Technology Commission (no. 11JC1404800).

\section{Acknowledgements}

The authors would like to thank Zhongping Zhou for his technical assistance and the anti-BPI-N antiserum used in the experiment.

\section{References}

Bartlett JA, Gakhar L, Penterman J, Singh PK, Mallampalli RK, Porter E \& McCray PB Jr 2011 PLUNC: a multifunctional surfactant of the airways. Biochemical Society Transactions 39 1012-1016. (doi:10.1042/ BST0391012)

Beamer LJ 2003 Structure of human BPI (bactericidal/permeabilityincreasing protein) and implications for related proteins. Biochemical Society Transactions 31 791-794. (doi:10.1042/BST0310791)

Bedford JM 1967 Fertile life of rabbit spermatozoa in rat uterus. Nature 213 1097-1099. (doi:10.1038/2131097a0)

Belleannee C, Thimon V \& Sullivan R 2012 Region-specific gene expression in the epididymis. Cell and Tissue Research 349 717-731. (doi:10.1007/ s00441-012-1381-0)

Boue F, Duquenne C, Lassalle B, Lefevre A \& Finaz C 1995 FLB1, a human protein of epididymal origin that is involved in the sperm-oocyte recognition process. Biology of Reproduction 52 267-278. (doi:10.1095/ biolreprod52.2.267)

Canny G \& Levy O 2008 Bactericidal/permeability-increasing protein (BPI) and BPI homologs at mucosal sites. Trends in Immunology 29 541-547. (doi:10.1016/j.it.2008.07.012)

Canny G, Levy O, Furuta GT, Narravula-Alipati S, Sisson RB, Serhan CN \& Colgan SP 2002 Lipid mediator-induced expression of bactericidal/ permeability-increasing protein (BPI) in human mucosal epithelia. PNAS 99 3902-3907. (doi:10.1073/pnas.052533799)

Carlsson M, Shukla S, Petersson AC, Segelmark M \& Hellmark T 2011 Pseudomonas aeruginosa in cystic fibrosis: pyocyanin negative strains are associated with BPI-ANCA and progressive lung disease. Journal of Cystic Fibrosis 10 265-271. (doi:10.1016/j.jcf.2011.03.004)

Chen CZ, Ou CY, Wang RH, Lee CH, Lin CC, Chang HY \& Hsiue TR 2012 The role of bactericidal/permeability-increasing protein in men with chronic obstructive pulmonary disease. COPD 9 197-202. (doi:10.3109/ 15412555.2011.654143)

Eckert M, Wittmann I, Rollinghoff M, Gessner A \& Schnare M 2006 Endotoxin-induced expression of murine bactericidal permeability/ increasing protein is mediated exclusively by toll/IL-1 receptor domain-containing adaptor inducing IFN- $\beta$-dependent pathways. Journal of Immunology 176 522-528.

Elsbach P \& Weiss J 1998 Role of the bactericidal/permeability-increasing protein in host defence. Current Opinion in Immunology 10 45-49. (doi:10.1016/S0952-7915(98)80030-7)

Gazzano-Santoro H, Parent JB, Grinna L, Horwitz A, Parsons T, Theofan G, Elsbach P, Weiss J \& Conlon PJ 1992 High-affinity binding of the bactericidal/permeability-increasing protein and a recombinant aminoterminal fragment to the lipid A region of lipopolysaccharide. Infection and Immunity 60 4754-4761.

Geraldes P, Yamagata M, Rook SL, Sassa Y, Ma RC, Clermont A, Gao B, Aiello LP, Feener EP \& King GL 2007 Glypican 4, a membrane binding protein for bactericidal/permeability-increasing protein signaling pathways in retinal pigment epithelial cells. Investigative Ophthalmology \& Visual Science 48 5750-5755. (doi:10.1167/iovs.070470)

Guinan EC, Barbon CM, Kalish LA, Parmar K, Kutok J, Mancuso CJ, Stoler-Barak L, Suter EE, Russell JD, Palmer CD et al. 2011 Bactericidal/permeability-increasing protein ( $\mathrm{rBPI} 21)$ and fluoroquinolone mitigate radiation-induced bone marrow aplasia and death. Science Translational Medicine 3 110ra118. (doi:10.1126/scitransImed. 3003126)

Haider SG 2004 Cell biology of Leydig cells in the testis. International Review of Cytology 233 181-241.

Hardy CM, Clydesdale G, Mobbs KJ, Pekin J, Lloyd ML, Sweet C, Shellam GR \& Lawson MA 2004 Assessment of contraceptive vaccines based on recombinant mouse sperm protein PH20. Reproduction 127 325-334. (doi:10.1530/rep.1.00016)

Haring R, Baumeister SE, Vlzke H, Drr M, Kocher T, Nauck M \& Wallaschofski H 2012 Prospective inverse associations of sex hormone concentrations in men with biomarkers of inflammation and oxidative stress. Journal of Andrology 33 944-950. (doi:10.2164/jandrol.111.015065)

Holweg A, Schnare M \& Gessner A 2011 The bactericidal/permeabilityincreasing protein $(\mathrm{BPI})$ in the innate defence of the lower airways. Biochemical Society Transactions 39 1045-1050. (doi:10.1042/ BST0391045) 
lovine NM, Elsbach P \& Weiss J 1997 An opsonic function of the neutrophil bactericidal/permeability-increasing protein depends on both its $\mathrm{N}$ - and C-terminal domains. PNAS 94 10973-10978. (doi:10.1073/pnas.94.20. 10973)

Klapcinska B, Jagsz S, Sadowska-Krepa E, Gorski J, Kempa K \& Langfort J 2008 Effects of castration and testosterone replacement on the antioxidant defense system in rat left ventricle. Journal of Physiological Sciences 58 173-177. (doi:10.2170/physiolsci.RP002208)

Krasity BC, Troll JV, Weiss JP \& McFall-Ngai MJ 2011 LBP/BPI proteins and their relatives: conservation over evolution and roles in mutualism. Biochemical Society Transactions 39 1039-1044. (doi:10.1042/BST0391039)

Leclair EE 2003 Four BPI (bactericidal/permeability-increasing protein)-like genes expressed in the mouse nasal, oral, airway and digestive epithelia. Biochemical Society Transactions 31 801-805. (doi:10.1042/ BST0310801)

Lefevre A, Martin RC, Chokomian S, Duquenne C \& Finaz C 1997 Characterization and isolation of SOB2, a human sperm protein with a potential role in oocyte membrane binding. Molecular Human Reproduction 3 507-516. (doi:10.1093/molehr/3.6.507)

Lennartsson A, Pieters K, Vidovic K \& Gullberg U 2005 A murine antibacterial ortholog to human bactericidal/permeability-increasing protein $(\mathrm{BPI})$ is expressed in testis, epididymis, and bone marrow. Journal of Leukocyte Biology 77 369-377. (doi:10.1189/jlb.0304159)

Luo XM, Yang QH, Wei J \& Ma LP 2012 Bactericidal permeability increasing protein inhibits lipopolysaccharide-mediated platelet activation in vitro. Zhongguo Shi Yan Xue Ye Xue Za Zhi 20 129-132.

Naz RK 2002 Molecular and immunological characteristics of sperm antigens involved in egg binding. Journal of Reproductive Immunology 53 13-23. (doi:10.1016/S0165-0378(01)00094-8)

Orgebin-Crist MC 1967 Sperm maturation in rabbit epididymis. Nature 216 816-818. (doi:10.1038/216816a0)

Palmer CD, Guinan EC \& Levy O 2011 Deficient expression of bactericidal/permeability-increasing protein in immunocompromised hosts: translational potential of replacement therapy. Biochemical Society Transactions 39 994-999. (doi:10.1042/BST0390994)

Primiani N, Gregory M, Dufresne J, Smith CE, Liu YL, Bartles JR, Cyr DG \& Hermo L 2007 Microvillar size and espin expression in principal cells of the adult rat epididymis are regulated by androgens. Journal of Andrology 28 659-669. (doi:10.2164/jandrol.107.002634)

Qiu X, Mistry A, Ammirati MJ, Chrunyk BA, Clark RW, Cong Y, Culp JS, Danley DE, Freeman TB, Geoghegan KF et al. 2007 Crystal structure of cholesteryl ester transfer protein reveals a long tunnel and four bound lipid molecules. Nature Structural \& Molecular Biology 14 106-113. (doi:10.1038/nsmb1197)

der Schaft DW, Toebes EA, Haseman JR, Mayo KH \& Griffioen AW 2000 Bactericidal/permeability-increasing protein (BPI) inhibits angiogenesis via induction of apoptosis in vascular endothelial cells. Blood 96 176-181.

der Schaft DW, Wagstaff J, Mayo KH \& Griffioen AW 2002 The antiangiogenic properties of bactericidal/permeability-increasing protein (BPI). Annals of Medicine 34 19-27. (doi:10.1080/078538902317338607)
Sipila P, Krutskikh A, Pujianto DA, Poutanen M \& Huhtaniemi I 2011 Regional expression of androgen receptor coregulators and androgen action in the mouse epididymis. Journal of Andrology 32 711-717. (doi:10.2164/jandrol.110.012914)

Turner TT 2011 Looking to the future of epididymal research: why this, why now. Journal of Andrology 32 705-710. (doi:10.2164/jandrol.111. 013003)

Turner TT \& Bomgardner D 2002 On the regulation of Crisp-1 mRNA expression and protein secretion by luminal factors presented in vivo by microperfusion of the rat proximal caput epididymidis. Molecular Reproduction and Development 61 437-444. (doi:10.1002/ mrd.10115)

Turner TT, Johnston DS, Finger JN \& Jelinsky SA 2007a Differential gene expression among the proximal segments of the rat epididymis is lost after efferent duct ligation. Biology of Reproduction 77 165-171. (doi:10.1095/biolreprod.106.059493)

Turner TT, Johnston DS, Jelinsky SA, Tomsig JL \& Finger JN 2007 b Segment boundaries of the adult rat epididymis limit interstitial signaling by potential paracrine factors and segments lose differential gene expression after efferent duct ligation. Asian Journal of Andrology 9 565-573. (doi:10.1111/j.1745-7262.2007.00302.x)

Wang L, Yuan Q, Chen S, Cai H, Lu M, Liu Y \& Xu C 2012 Antimicrobial activity and molecular mechanism of the CRES protein. PLOS ONE 7 e48368. (doi:10.1371/journal.pone.0048368)

Weersink AJ, van Kessel KP, van den Tol ME, van Strijp JA, Torensma R, Verhoef J, Elsbach P \& Weiss J 1993 Human granulocytes express a $55-k D a$ lipopolysaccharide-binding protein on the cell surface that is identical to the bactericidal/permeability-increasing protein. Journal of Immunology 150 253-263.

Weiss J, Elsbach P, Olsson I \& Odeberg H 1978 Purification and characterization of a potent bactericidal and membrane active protein from the granules of human polymorphonuclear leukocytes. Journal of Biological Chemistry 253 2664-2672.

Yamagata M, Rook SL, Sassa Y, Ma RC, Geraldes P, Goddard L, Clermont A, Gao B, Salti H, Gundel R et al. 2006 Bactericidal/permeabilityincreasing protein's signaling pathways and its retinal trophic and anti-angiogenic effects. FASEB Journal 20 2058-2067. (doi:10.1096/ 05-5662com)

Yano R, Matsuyama T, Kaneko T, Kurio H, Murayama E, Toshimori K \& lida H 2010 Bactericidal/permeability-increasing protein is associated with the acrosome region of rodent epididymal spermatozoa. Journal of Andrology 31 201-214. (doi:10.2164/jandrol.109.007880)

Received 27 March 2013

First decision 15 April 2013

Revised manuscript received 27 May 2013

Accepted 5 June 2013 